\title{
Recuperação de rios urbanos: da interdependência e sincronicidade dos processos de desnaturalização em rios e bacias hidrográficas urbanas
}

\section{Recovery of urban rivers: the interdependence and synchronicity of denaturalization processes in urban rivers and watersheds}

\author{
Juliana Wilse Landolfi Texeira de Carvalho* $₫(\mathbb{D}$, Fernando Helmuth Syring Marangon $\bowtie$ (D), \\ Irani dos Santos $\bowtie$ (D) \\ Laboratório de Hidrogeomorfologia, Universidade Federal do Paraná, Curitiba, Paraná, Brasil \\ E-mails: fhsmarangon@gmail.com (FHSM); irani69@gmail.com (IS) \\ *E-mail para correspondência: ju_wlt@hotmail.com
}

Recebido (Received): 16/09/2019

\begin{abstract}
Resumo: O presente estudo avalia do ponto de vista teórico e prático a interdependência e sincronicidade dos processos de desnaturalização que ocorrem no rio e na bacia hidrográfica em ambientes urbanos. De maneira complementar, avalia como a interdependência destes processos é abordada nos trabalhos de recuperação de rios urbanos. Do ponto de vista teórico, verificou-se que há uma gama de projetos de recuperação de rios urbanos degradados com diferentes abordagens e propósitos, e que tais projetos se voltam especialmente aos processos que ocorrem estritamente nos rios. A literatura sugere que esta pode ser a causa do insucesso de muitos dos projetos de recuperação de rios urbanos. A avaliação prática foi realizada na bacia hidrográfica Córrego do Aviário, localizada em área urbana da cidade de Curitiba/PR. A área foi compartimentada em Ottobacias, para que fosse realizada a quantificação da desnaturalização dos elementos rio e bacia hidrográfica em cada uma das unidades de análise. A aplicação prática permite concluir que as modificações verificadas na rede de drenagem são um reflexo da impermeabilização do solo ou desnaturalização das Ottobacias. Espera-se que na medida em que aumentem as porções impermeáveis das Ottobacias esta condição esteja refletida na alteração da rede de drenagem. De maneira geral, a metodologia empregada no presente estudo pode ser utilizada como ferramenta para diagnóstico no planejamento do espaço urbano e na recuperação de rios degradados.
\end{abstract}

Palavras-chave: Hidrologia Urbana; Áreas Impermeáveis; Canalização; Desnaturalização.

Abstract: The current study evaluates, from a theoretical and practical perspective, the interdependence and synchronicity among denaturalization processes that occur in urban rivers and watersheds. In a complementary way, it assesses how the interdependence of these processes is approached in urban river recovery projects. From the theoretical perspective, it was found that there is a range of recovery projects for degraded urban rivers with different approaches and purposes and that such projects are mainly focused on the processes that occur strictly in the rivers. The literature suggests that it may be the cause of the failure of many urban river restoration projects. The practical evaluation was carried out in the córrego do Aviario watershed, located in an urban area of Curitiba/PR. The area was compartmentalized in Ottobacias so that the denaturalization of the river and watershed elements could be quantified in each of the units of analysis. The practical application allows concluding that the modifications verified in the drainage network are the reflection of soil impermeabilization or Ottobacias' denaturalization. It is expected that as the Ottobacias impervious areas increase, this condition will be reflected in the drainage network denaturalization. In general, the methodology used in this study can be used as a diagnostic tool for urban planning and the recovery of degraded rivers.

Keywords: Urban Hydrology; Impervious Areas; Canalization; Denaturalization. 


\section{Introdução}

A urbanização é uma das tendências mais transformadoras do século XXI (WWC, 2018) e carrega consigo fortes implicações em relação a geração de impactos nas mais diversas esferas e escalas. Muitos destes impactos são verificados na dinâmica hídrica das bacias hidrográficas, onde o crescimento da malha urbana se dá juntamente com a desnaturalização dos rios e dos processos envolvidos na dinâmica hídrica das bacias de drenagem.

As alterações mais visíveis se dão diretamente nos canais fluviais. Em função do crescimento urbano, muitos rios são canalizados com o objetivo de viabilizar o aumento de áreas disponíveis para ocupação e de solucionar problemas ligados às inundações e propagação de doenças de veiculação hídrica. Entende-se como obras de canalização as obras de engenharia praticadas no canal fluvial, sejam elas alargamento e aprofundamento da calha fluvial, retificação do canal, construção de canais artificiais, proteção de margens, diques ou obras de desassoreamento (ASSUMPÇÃO; MARÇAL, 2012; CUNHA, 2012). Tais obras, em geral, transformam os leitos dos rios em perfis regulares, extinguem meandros, encurtam o curso do rio e, por consequência, aumentam a velocidade de escoamento, picos de vazão máxima, erosão de margens e alteram o ecossistema aquático. Em ambientes mais densamente urbanizados, a rede de drenagem é transformada em canalização subterrânea, tornando a paisagem urbana mais profundamente alterada.

O termo desnaturalização, utilizado em diferentes aplicações em outras áreas do conhecimento, atualmente começa a ser também utilizado na literatura das ciências hidrológicas. Cunha (2012) e Sartório (2018) utilizam-se do termo associado a ambientes fluviais, para referirem-se à perda de características naturais e à artificialização de cursos d’água, associados à geração de impactos no meio físico e biótico.

Cunha (2012) aborda questões relacionadas a rios desnaturalizados por meio de obras de canalização. De acordo com a autora, o grau de degradação do canal depende do nível de alteração de sua dinâmica e morfologia. As mudanças hidrológicas, geomorfológicas e bióticas podem ser verificadas tanto no trecho alterado, quanto nos trechos a jusante e a montante. Botelho (2011) e Stevaux e Latrubesse (2017) também destacam que, devido ao seu equilíbrio dinâmico, a alteração de um trecho de rio é transmitida ao rio como um todo. A canalização de um dado trecho intensifica os processos erosivos à montante, bem como transfere volume de água, sedimentos e poluentes para jusante.

Sartório (2018) investiga o processo evolutivo da desnaturalização do sistema fluvial dos canais da Costa e Bigossi em Vila Velha/ES. Conclui que a canalização dos rios, a criação de novos canais e a impermeabilização da bacia de drenagem, alteraram o equilíbrio do sistema, gerando um ambiente mais vulnerável às inundações.

Diante de cenários de degradação dos rios urbanos e do aumento da intensidade e frequência das inundações, projetos de recuperação de rios urbanos, com diferentes abordagens vem sendo desenvolvidas. Restauração, reabilitação, remediação, revitalização e renaturalização são alguns dos conceitos encontrados na literatura, sendo os dois últimos os mais difundidos e encontrados em projetos aplicados.

O termo restauração refere-se ao conjunto de ações que permitem que o rio retorne às suas condições hidrológicas, geomorfológicas e bióticas originais, incluindo a zona ripária (RUTHERFURD et al. 2000a). Enquanto a restauração propõe o retorno ao estado original do rio, a reabilitação é representada por ações que possibilitem o retorno parcial das condições biológicas e físicas da sua condição original (FINDLAY; TAYLOR, 2006). Remediação, por sua vez, possui objetivo de melhorar as condições ecológicas de um rio e resulta na formação de um ambiente diferente do original. Ela é aplicada em casos em que os impactos ambientais constatados foram muito intensos, inviabilizando os processos de reabilitação e restauração (RUTHERFURD et al. 2000a).

Machado (2008) verifica que não há um conceito bem definido ou legislação específica no Brasil que defina o termo revitalização. Apesar das diversas abordagens do conceito, é consenso que a revitalização abrange uma gama de ações no sentido de recuperar, conservar e preservar as funções ou serviços que os rios desempenham, sejam elas biofísicas, econômicas, estéticas ou culturais. Os rios Stony e Muddy (Boston/EUA), Cheonggyecheon (Coreia do Sul), Torrens (Austrália), La Piedad e Churubusco (Cidade do México/México) e os córregos Tiquatira (São Paulo/SP), Sapé (São Paulo/SP) e $1^{\circ}$ de Maio (Belo Horizonte/MG) são exemplos de projetos de revitalização que se utilizaram da construção de Parques Lineares para melhoria na qualidade ambiental dos cursos d'água (MARTINS, 2015).

A renaturalização, por sua vez, é definida por Binder (2001) como processo complexo de retorno às condições sustentáveis de um determinado rio, iniciado com princípios de revitalização, precedido de recomposição de substratos e margens, recuperação de áreas úmidas, biota aquática e conservação de áreas 
naturais de inundação. Binder (2001) reitera que a renaturalização não significa a volta à paisagem original não modificada pelo homem, mas corresponde a recomposição do desenvolvimento sustentável do rio.

A renaturalização do Rio Isar, na Alemanha, descrito por Binder (2008) é um dos exemplos de recuperação de rios degradados por obras de canalização. Nele foi realizada a remoção dos diques de concreto, alargamento da seção do rio e aplainamento das margens. O material de concreto foi realocado no fundo para reforçar o substrato e criar possíveis espaços para o habitat de novas espécies. O rio Anacostia, localizado em área densamente urbanizada de Washington (EUA) também passou por obras de renaturalização, onde foram promovidas ações para recuperação de áreas úmidas e da mata ciliar, remoção de plantas invasoras, estabilização bancos e instalação de trash-traps para diminuição da poluição hídrica (AWS, 2013). Outros exemplos de experiências internacionais são o rio Regge (Holanda) (Boher e Bressers, 2011) e o rio Mapocho (Chile) (KATZ et al. 2009), com intervenções realizadas também diretamente dos rios.

No Brasil, destacam-se os projetos de renaturalização realizados no rio das Velhas, em Minas Gerais, e no rio Tijuco Preto, em São Paulo. Dentre as práticas adotadas no rio das Velhas, estão a reconstrução de habitats para a biodiversidade, replantio de mata ciliar, conservação de áreas úmidas e construção de estações de tratamento de esgoto (DINIZ et al. 2008). No rio Tijuco Preto, inserido em área densamente urbanizada da cidade de São Carlos/SP, foram retiradas as estruturas de concreto, foi feita a reconstrução do habitat fluvial com madeiras e gabiões para favorecimento da formação de remansos e corredeiras. Foram também eliminados pontos de despejo de efluentes, realizadas desapropriações em terrenos de APP, além da construção de um parque linear (BARBOSA et al. 2005).

Nota-se que as iniciativas de recuperação mencionadas anteriormente apresentam como característica comum a rede de drenagem como objeto de intervenção. Nesse sentido, Palmer et al. (2010) constatam que a ausência de uma visão sistêmica e integrada entre rio e bacia hidrográfica pode ser o motivo de insucesso de muitas das obras de revitalização ou renaturalização de rios urbanos, que se concentram, em geral, apenas nas características do canal físico. Evidenciam ainda que muito mais deve ser feito para restaurar fluxos impactados por múltiplos estressores do que reconfigurar canais e aumentar a complexidade estrutural com meandros, pedregulhos, madeira ou outras estruturas que renaturalizem processos, mesmo que de modo artificial.

Palmer e Ruhi (2019) elaboraram uma revisão sobre as relações entre regime de escoamento, biota e processos ecossistêmicos na restauração de rios. Constatam a grande dificuldade em recuperar rios degradados. De acordo com os autores, o sucesso depende de ir além da restauração do canal fluvial, alcançando, portanto, a conectividade hidrológica entre um rio e seus arredores. Rutherfurd et al. (2000b), por sua vez, inferem que as características da bacia, tais como uso do solo e dinâmica de escoamento superficial e subsuperficial podem influir diretamente nas características do rio. Como critério para compreensão dos processos e também para posterior seleção de áreas prioritárias para ação, os autores propõe dividir a área de estudo em unidades de análise.

Tais inferências levam à compreensão de que se faz necessário também lançar o olhar aos processos de desnaturalização que ocorrem nas bacias urbanas. Isto porque o ambiente urbano construído tem forte influência também nas características da dinâmica hídrica das vertentes, especialmente em decorrência da impermeabilização do solo. Estudos que avaliam os efeitos da urbanização no balanço hídrico, tais como Mitchell et al. (2001), Tucci (2002; 2008), Lekkas et al. (2008), Lee et al. (2010), Mejía (2014) e Carvalho (2016) evidenciam que o incremento nas áreas impermeáveis diminuem os índices de evapotranspiração, de infiltração da água no solo, aumentam o escoamento superficial e os picos de vazão máxima durante eventos pluviométricos. Os efeitos no balanço hídrico ligados diretamente ao volume e velocidade da vazão afetam diretamente a dinâmica fluvial. Durante eventos pluviométricos há a intensificação dos processos hidrológicos e das inundações, bem como rápido carreamento de poluentes difusos da bacia de drenagem diretamente para o rio. Durante períodos de estiagem, há diminuição do escoamento de base, alterando o regime de escoamento e a condição ecossistêmica do rio. Tais efeitos caracterizam a desnaturalização de processos do ciclo hidrológico em ambiente urbano.

Destaca-se ainda que o percentual de impermeabilização do solo é um importante parâmetro para determinação do grau de desnaturalização da bacia hidrográfica. Os estudos citados sobre balanço hídrico urbano (MITCHELL et al. 2001; TUCCI, 2002, 2008; LEKKAS et al. 2008; LEE et al. 2010; MEJÍA, 2014 e CARVALHO, 2016) evidenciam que a impermeabilização do solo é indicador do processo da urbanização, sendo capaz de sintetizar vários elementos relativos aos processos hidrológicos em bacias hidrográficas. 
Um dos grandes desafios para os gestores urbanos é o de visualizar o rio no contexto da bacia, a partir de uma compreensão sistêmica. O rio não é um elemento isolado. Por este motivo, não é possível conhecer seu funcionamento sem compreender os fenômenos que se dão em seu entorno, assim como não é possível restaurar o rio sem considerar restaurar alguns dos processos hidrológicos que se dão na bacia, mesmo que artificialmente. Assim, destaca-se a problemática associada ao olhar centrado exclusivamente para o rio em processos diagnósticos e em projetos de recuperação de rios degradados, sendo que esta degradação resulta da interação com os processos que ocorrem na bacia hidrográfica.

Com base nas questões expostas, este trabalho tem por objetivo avaliar do ponto de vista teórico e prático a interdependência e sincronicidade dos processos de desnaturalização que ocorrem no rio e na bacia hidrográfica. De maneira complementar, buscou também avaliar como a interdependência destes processos é abordada nos trabalhos de recuperação de rios urbanos.

Uma revisão teórica foi realizada a cerca de projetos de recuperação de rios urbanos, buscando identificar a abordagem utilizada. Destaca-se não foram encontrados estudos na literatura que investiguem de forma direta o quanto os processos de desnaturalização dos rios estão atrelados aos processos hidrológicos que ocorrem na bacia em ambientes urbanos.

Uma avaliação prática foi conduzida na bacia hidrográfica córrego do Aviário, localizada em área urbana da cidade de Curitiba/PR. A área foi compartimentada em Ottobacias, para que fosse realizada a quantificação da desnaturalização dos elementos rio e bacia em cada uma das unidades de análise. O critério para definição do grau de desnaturalização das bacias foi o percentual de impermeabilização do solo. Para o rio, o critério foi o grau de interferência antrópica e o tipo de obra de canalização empregada.

A bacia hidrográfica córrego do Aviário foi escolhida pois apresenta características comuns à realidade de muitas das bacias hidrográficas urbanas brasileiras, tais como diversidade de usos da terra, impermeabilização de importante percentual do solo, poluição hídrica, inundações frequentes e múltiplas obras de canalização nos rios. É também uma amostra representativa em relação ao contexto da cidade de Curitiba devido a sua diversidade de usos, incluindo áreas verdes, áreas residenciais e institucionais e devido ao fato de apresentar um percentual médio de áreas impermeabilizadas em relação ao contexto da cidade (CARVALHO, 2016).

\section{Materiais e métodos}

\subsection{Descrição da área de estudo}

Com $2.7 \mathrm{~km}^{2}$, a bacia hidrográfica do córrego do Aviário está inserida na bacia do rio Belém (Figura 1). Esta, por sua vez, drena cerca de $20 \%$ da cidade de Curitiba/PR e abrange a área mais densamente urbanizada do município. A área abrange parte dos bairros Jardim das Américas, Jardim Botânico, Guabirotuba e Prado Velho, cuja ocupação é caracterizada por áreas residenciais, comerciais e institucionais, incluindo os Campus Politécnico e Botânico da UFPR (Universidade Federal do Paraná), a PUC-PR (Pontifícia Universidade Católica do Paraná) e a FIEP (Federação das Indústrias do Estado do Paraná). A área de estudo localiza-se integralmente no primeiro planalto paranaense. Na bacia predomina a formação Guabirotuba, recoberta por sedimentos de origem flúvio-lacustre de idade holocênica-pleistocênica (MINEROPAR, 2006). A altitude da área de estudo varia de $880 \mathrm{~m}$ a $925 \mathrm{~m}$.

O córrego do Aviário nasce nas dependências do Campus Politécnico da UFPR e deságua no rio Belém. $\mathrm{O}$ rio principal é alimentado por outros nove afluentes que se distribuem regularmente por toda a bacia. Em campo, constatou-se que a qualidade ambiental do córrego do Aviário deprecia no sentido de jusante, em função da presença de fontes pontuais e difusas de poluição, obras de canalização, degradação de áreas úmidas, ausência de mata ciliar em vários trechos e ocupações irregulares.

Devido à associação de características climáticas, baixa permeabilidade natural dos solos, alto percentual de impermeabilização do solo e mal dimensionamento dos sistemas de drenagem urbana, a bacia hidrográfica do rio Belém sofreu mais de 200 episódios de inundação nos últimos 30 anos (GOUDARD, 2018), sendo que muitos deles ocorreram também no contexto da bacia hidrográfica córrego do Aviário, especialmente na área confluência com o rio Belém. Dentre os eventos pluviométricos mais significativos e recentes em termos de impactos, destaca-se o episódio de 21/02/2019, com precipitação de $119,6 \mathrm{~mm} / 24 \mathrm{~h}$. A Figura 2 exibe imagens do evento na região da Vila Torres (A), próximo à foz do córrego do Aviário e na região da UFPR campus Politécnico (C e D). 


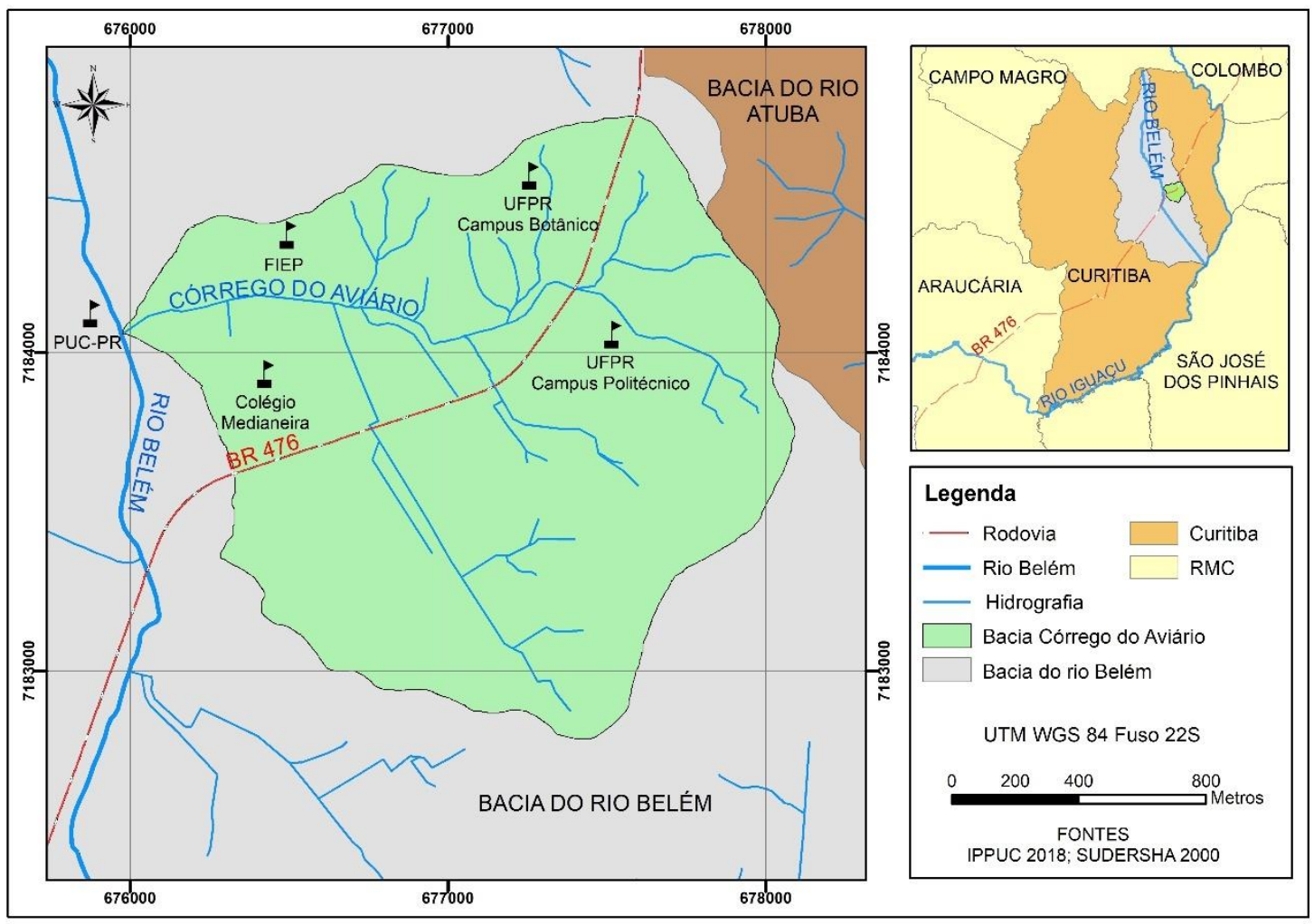

Figura 1: Mapa de localização.

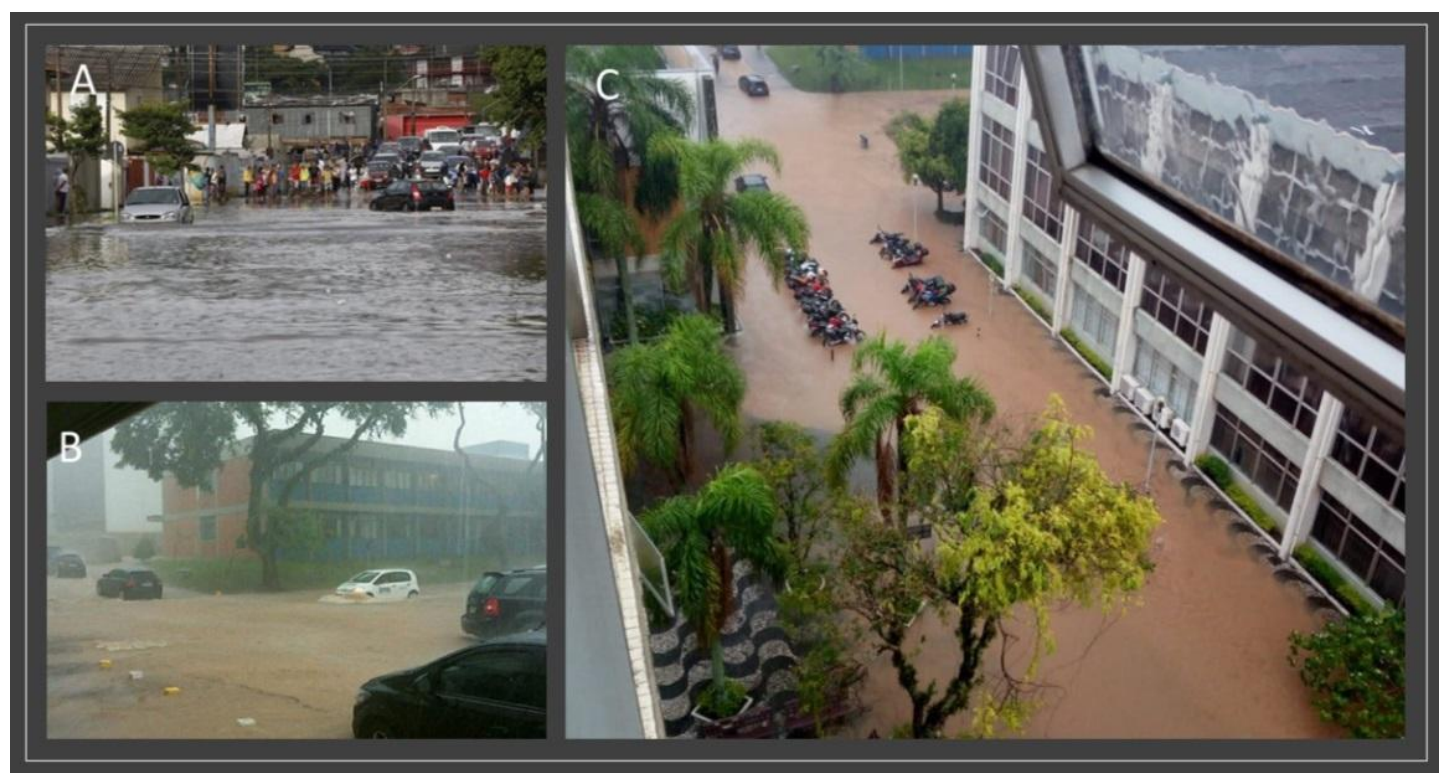

Figura 2: Inundação de 21/02/2019. Fonte: Imagem A (Tribuna do Paraná); Imagens B e C (Autoria Desconhecida).

\subsection{Desnaturalização de bacias hidrográficas e rios urbanos}

Como critério para compreensão e avaliação dos processos (conforme proposto por RUTHERFORD et al. 2000b) de desnaturalização na bacia hidrográfica, a área de estudo foi compartimentada em unidades de análise. A metodologia escolhida foi a delimitação de Ottobacias, de acordo com o modelo proposto por Pfafstetter (1989). Ottobacias são áreas de contribuição dos trechos da rede hidrográfica, delimitadas de acordo com um método hierárquico de subdivisão e codificação de sub-bacias, relacionando trechos de rio à sua respectiva área de drenagem. Tendo como base a topografia do terreno, o método permite detalhamento do sistema hídrico, facilitando a visualização de impactos provenientes de determinadas ações em áreas específicas. 
A delimitação foi realizada em ambiente SIG, a partir da análise da rede de drenagem e da topografia. No método de Pfafstatter (1989), as quatro maiores bacias identificadas são denominadas Ottobacias, as quais recebem códigos dos números pares 2, 4, 6 e 8, atribuídos de jusante para montante ao longo do rio principal. A área de drenagem correspondente à nascente do rio principal é a de número 9. As áreas restantes são chamadas Interbacias, sendo elas numeradas de acordo com a mesma lógica, no entanto, com os números ímpares 1,3,5 e 7. A Interbacia 3, localiza-se sempre entre as Ottobacias 2 e 4, a 5, entre 4 e 6, e assim sucessivamente. Todas as bacias identificadas devem ser subdivididas de modo que, ao fim, todos os afluentes estejam em áreas distintas. Às subdivisões, acrescenta-se mais um número. À exemplo: 21, 22, 23, com suas novas subdivisões $221,222,223$, e assim progressivamente.

O parâmetro escolhido para determinação do nível de desnaturalização das Ottobacias foi o percentual de impermeabilização do solo. Conforme anteriormente citado, estudos sobre balanço hídrico urbano, tais como Mitchell et al. (2001), Tucci (2002; 2008), Lekkas et al. (2008), Lee et al. (2010), Mejía (2014) e Carvalho (2016) evidenciam que a impermeabilização do solo é indicador do processo da urbanização, sendo capaz de sintetizar vários elementos relativos à bacia no contexto hidrológico e, portanto, o grau de desnaturalização da mesma.

O mapeamento de áreas permeáveis e impermeáveis foi realizado com base na fotointerpretação de imagens orbitais, disponibilizadas pelo Google Earth Proo. Edificações, calçadas e ruas foram classificadas como impermeáveis. Gramados, pavimentos semipermeáveis e áreas vegetadas, foram classificadas como permeáveis. Os elementos foram vetorizados manualmente, dado o tamanho reduzido da área de estudo e possibilidade de uma maior escala de detalhe.

Após a determinação do percentual de impermeabilização, as Ottobacias foram classificadas por grau de desnaturalização conforme abaixo:

- Muito Baixo (de 0\% a 20\% de áreas impermeáveis)

- Baixo (20,1\% a $40 \%$ de áreas impermeáveis)

- Médio (40,1\% a $60 \%$ de áreas impermeáveis)

- Alto $(60,1 \%$ a $80 \%$ de áreas impermeáveis)

- Muito Alto (80,1\% a $100 \%$ de áreas impermeáveis)

Para classificação da condição dos corpos hídricos, foi considerada apenas a condição física do leito fluvial. Assim como Cunha (2012), este artigo trata de rios desnaturalizados, degradados por meio de obras de canalização. As condições do rio consideradas na área de estudo foram leito não modificado (natural), leito canalizado aberto e leito canalizado subterrâneo.

A condição do leito dos corpos hídricos foi aferida in situ, com auxílio de aparelho GPS. Os dados coletados foram exportados para o software SIG, onde então foram feitas correções no curso do córrego principal e dos afluentes, bem como realizada a classificação do leito para cada segmento de rio. Foi considerada apenas a modalidade predominante em cada umas das unidades de análise.

Para verificação das relações existentes entre grau de desnaturalização das Ottobacias e da condição do leito fluvial, foram realizadas algumas análises estatísticas. Primeiramente, foi efetuada a estatística descritiva básica das variáveis analisadas (área da bacia e percentual de área impermeabilizada) para cada categoria, bem como a distribuição de frequências relativa e absoluta acumulada da variável "percentual impermeável".

Em seguida, foram elaborados gráficos de caixa (BoxPlot), utilizados para avaliar visualmente a distribuição empírica dos dados, em relação à impermeabilização e modificações dos canais de drenagem. Adicionalmente, para avaliar se as proporções de áreas impermeabilizadas em Ottobacias com canais modificados diferem significativamente de Ottobacias com canais naturais foi aplicado o teste estatístico não paramétrico de Kruskal e Wallis (1952).

\section{Resultados e discussões}

Os dados obtidos através do mapeamento de áreas permeáveis e impermeáveis (Figura 3) indicam que 53,8\% do solo na bacia córrego do Aviário está impermeabilizado. Este percentual é inferior ao da bacia hidrográfica do rio Belém, que, na área de drenagem definida até a seção transversal de controle, Estação Fluviométrica Prado Velho, apresenta $72 \%$ de impermeabilização do solo (CARVALHO, 2016). A representatividade de áreas impermeáveis nas Ottobacias se dá de forma bastante heterogênea, variando de zero a $83 \%$. 


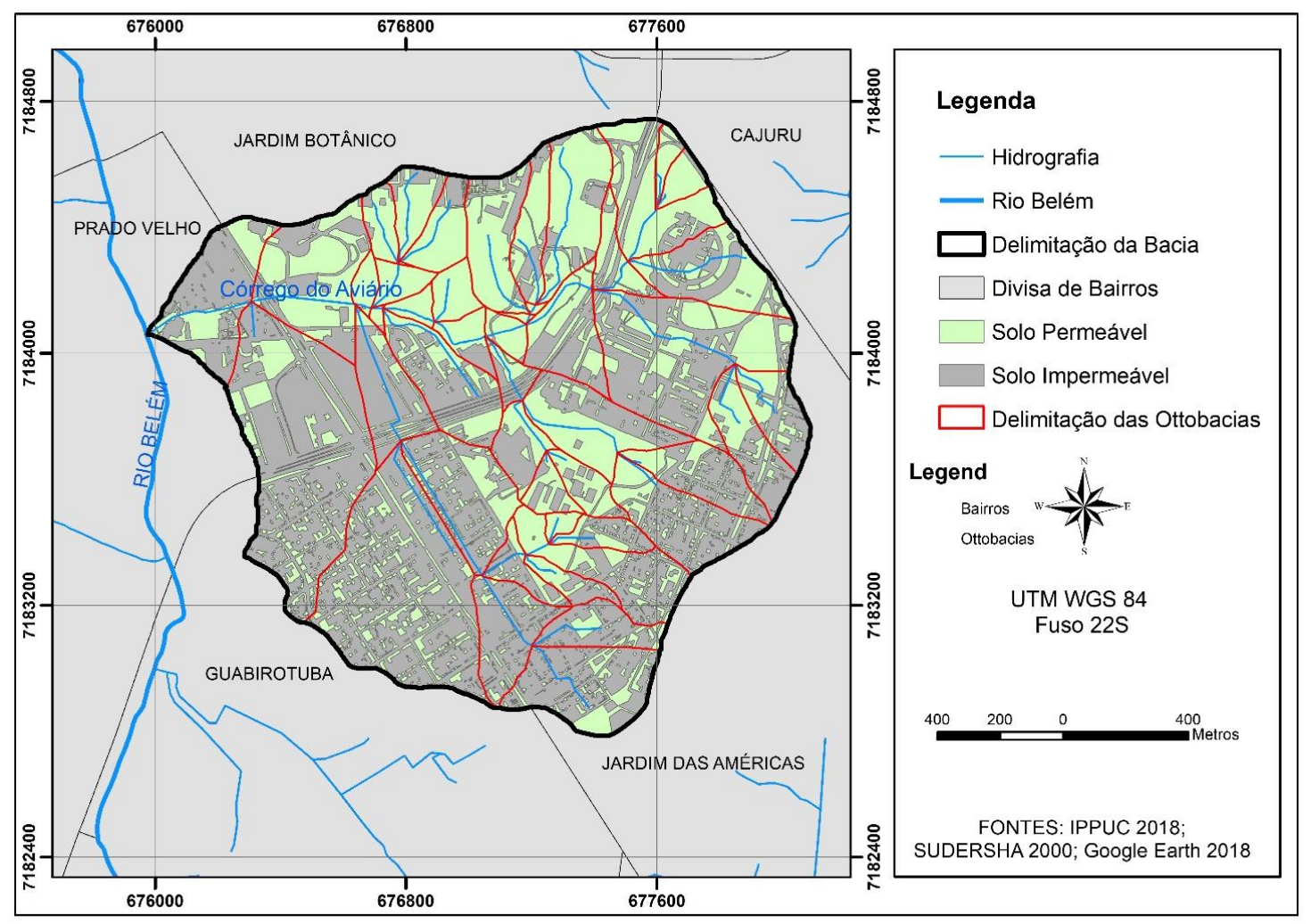

Figura 3: Mapa de áreas permeáveis e impermeáveis.

Isso se deve, em especial, à heterogeneidade espacial da área de estudo, com a presença de instituições educacionais (UFPR, FIEP e PUC-PR) nas porções norte, nordeste e central da bacia, onde predominam as áreas vegetadas; e com a presença de comércios e residências nas porções sul e oeste, onde há maior densidade de edificações, ruas e calçadas. As áreas permeáveis se restringem à jardins residenciais, pequenas praças e canteiros públicos.

Mesmo apresentando percentual de impermeabilização inferior à bacia hidrográfica do rio Belém, nota-se alto grau de desenvolvimento urbano na área de estudo, com consequente desnaturalização dos processos hidrológicos e intensificação dos problemas ligados a dinâmica hídrica em meio urbano. A impermeabilização de 53,8\% da área de uma bacia traz significativas alterações no regime natural de escoamento, diminuindo a infiltração da água no solo, aumentando os picos de vazão máxima e, consequentemente, aumentando risco, frequência e magnitude das inundações.

Dados os critérios metodológicos descritos na seção anterior, um segundo produto cartográfico foi gerado (Figura 4). O mapa de desnaturalização por Ottobacia e condições do leito fluvial retrata a espacialização de ambos os elementos, bem como esboça as possíveis relações entre as condições do rio e da bacia.

Visualmente, constata-se que nas unidades de análise menos desnaturalizadas, localizadas na porção norte, há predominância de canais não modificados. Nas unidades mais desnaturalizadas, entretanto, prevalecem os canais modificados e, em especial, a categoria "canalizado subterrâneo". As bacias 321, 351, 361, que possuem $100 \%$ de solo permeável, encontram-se inseridas no maior fragmento de vegetação do campus Botânico da UFPR, onde o rio é natural em toda sua extensão. Os maiores percentuais de desnaturalização, por sua vez, são encontrados nas bacias 211 e 251, situadas nas porções residenciais oeste e sul, onde o rio é canalizado subterrâneo.

A Figura 4 evidencia o predomínio de áreas alteradas pela expansão urbana, tanto ao que se refere à impermeabilização do solo, quanto à modificação dos canais de drenagem via retificação a canalização. A Tabela 1 apresenta dados gerais da bacia em relação a extensão e porcentagem de cada categoria de leito fluvial encontrada na área em estudo, com evidente predomínio de rios na condição "canalizado subterrâneo" $(56 \%)$. A categoria "canalizado aberto" corresponde a apenas $10 \%$ da extensão total dos córregos, enquanto que "natural" representa $34 \%$. 


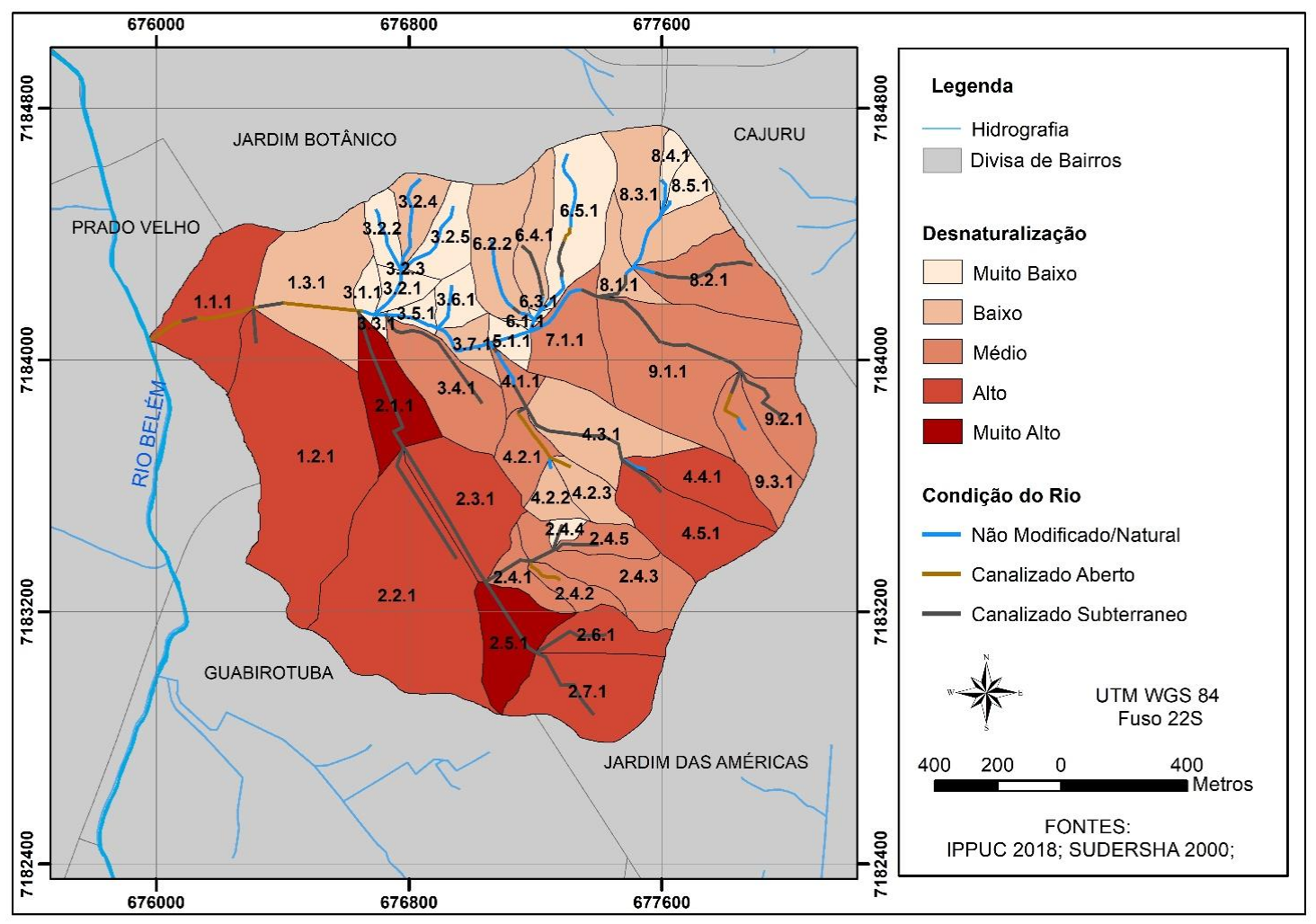

Figura 4: Mapa de desnaturalização de rios e Ottobacias.

Tabela 1: Condição do Leito Fluvial.

\begin{tabular}{ccc}
\hline Categoria & Extensão (Km) & Representatividade (\%) \\
\hline Canalizado subterrâneo & 5,8 & $56 \%$ \\
Canalizado aberto & 1,1 & $10 \%$ \\
Não modificado/natural & 3,5 & $34 \%$ \\
\hline
\end{tabular}

A Tabela 2 e Figura 4 apresentam a estatística descritiva básica e distribuição de frequência das Ottobacias. Ressalta-se que os valores de área total e proporções de áreas impermeabilizadas não se ajustam a distribuição normal (dados não apresentados).

Tabela 2: Estatística descritiva básica das variáveis analisadas.

\begin{tabular}{lllll}
\hline \multirow{2}{*}{ Categoria } & \multicolumn{5}{c}{ Área total das Ottobacias (ha) } \\
& Mínimo & Média & Máximo & $\boldsymbol{\sigma}$ \\
\hline Canalizado subterrâneo & 0,73 & 8,97 & 28,91 & 7,60 \\
Canalizado aberto & 1,95 & 5,96 & 12,00 & 3,93 \\
Não modificado/natural & 0,03 & 2,86 & 8,88 & 2,62 \\
\hline \multirow{2}{*}{ Categoria } & \multicolumn{4}{l}{ Porção de área impermeável (\%) } \\
& Mínimo & Média & Máximo & $\boldsymbol{\sigma}$ \\
\hline Canalizado subterrâneo & $1 \%$ & $57 \%$ & $83 \%$ & $20 \%$ \\
Canalizado aberto & $29 \%$ & $49 \%$ & $69 \%$ & $13 \%$ \\
Não modificado/natural & $0 \%$ & $19 \%$ & $64 \%$ & $18 \%$ \\
\hline Non
\end{tabular}

A Figura 5 apresenta a distribuição de frequências das condições do leito fluvial avaliadas. Neste sentido, é possível observar que na bacia do Aviário os canais de drenagem se dividem basicamente entre duas condições: "canalizado subterrâneo" ou "não modificado/natural". Assim, as Ottobacias com rios com condição "canalizado aberto" apresentam a menor representatividade na área de estudo analisada, sendo predominantes em apenas 6 das 47 Ottobacias, ou seja, em apenas 12,8\% delas. Uma inferência possível sob este aspecto é a de que, ao longo do tempo, uma vez consumada a condição de modificação dos canais, 
inicialmente categorizados como "canalizado aberto", haja uma tendência de transformação para a condição "canalizado subterrâneo".

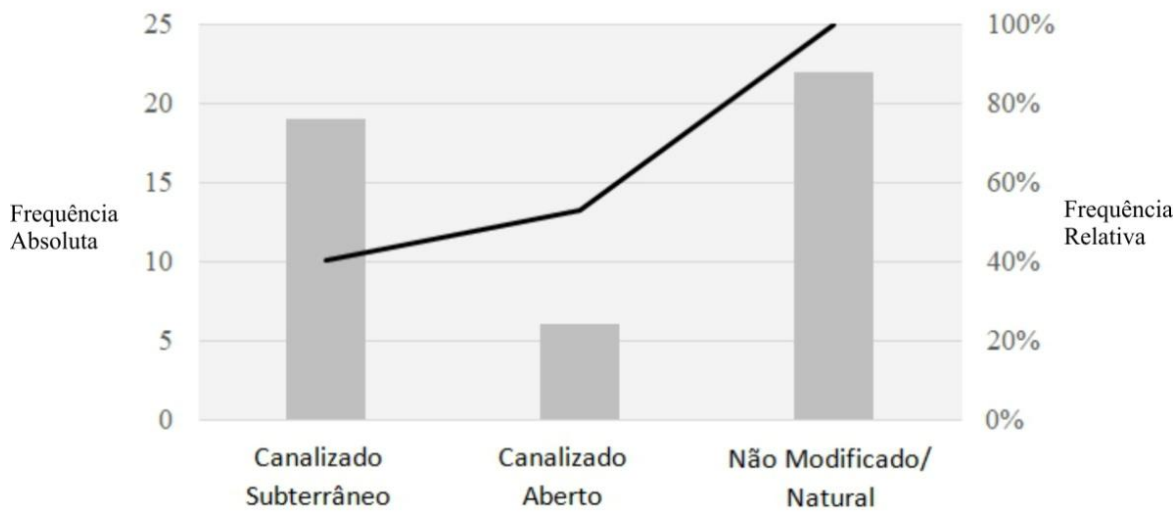

Figura 5: Distribuição de frequência das categorias de condição dos canais de drenagem.

A Figura 6 apresenta o gráfico de caixa (BoxPlot) que relaciona a dispersão das áreas das Ottobacias e a proporção de suas áreas impermeáveis com condição dos seus respectivos canais de drenagem. Neste gráfico, a haste inferior representa o menor elemento da amostra, enquanto a superior representa o maior. As caixas, por sua vez, apresentam três quartis $(\mathrm{Q} 1, \mathrm{Q} 2$ e Q3), os quais descrevem valores dados a partir do conjunto de observações em ordem crescente. Q1 é o número que separa $25 \%$ das observações abaixo e $75 \%$ acima, enquanto Q3 separa $75 \%$ das observações abaixo e $25 \%$ acima. Q2 é a mediana e, portanto, deixa $50 \%$ das observações abaixo e 50\% das observações acima. $\mathrm{O}$ "X" representa a média.

A Figura 6 demonstra indícios de um ordenamento das proporções de áreas impermeabilizadas nas Ottobacias em função das condições de seus respectivos canais de drenagem. Nota-se que, apesar de apresentar maior dispersão, as unidades de análise cujos canais permanecem inalterados apresentam as menores taxas de impermeabilização. Por outro lado, unidades cujos canais apresentam o maior grau de modificação (leito canalizado subterrâneo) possuem também as maiores taxas de impermeabilização verificadas, corroborando com a espacialização visível na Figura 3.

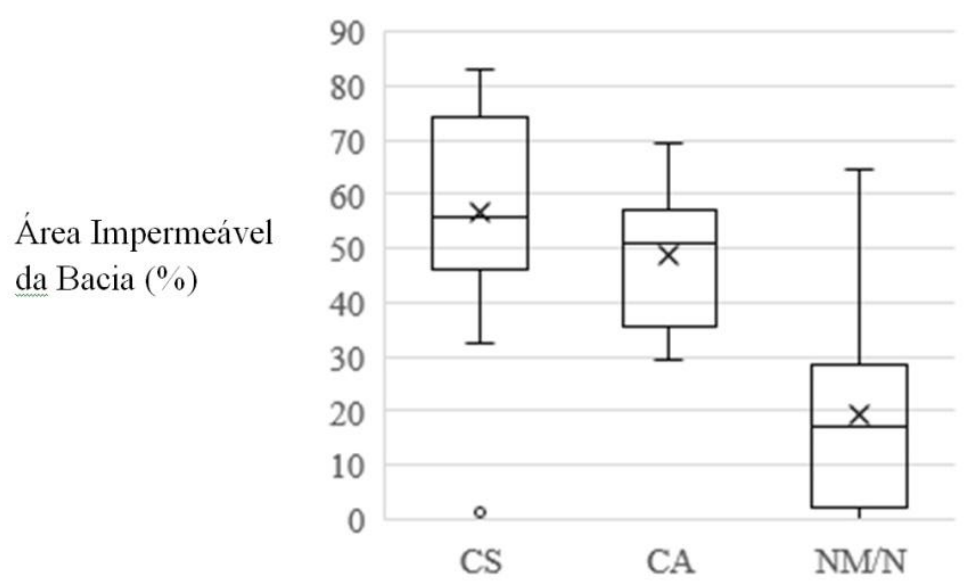

Figura 6: Gráfico de caixa para avaliação da distribuição das variáveis entre as categorias analisadas (percentual de áreas impermeabilizadas das Ottobacias). Nota: CS é leito canalizado subterrâneo; CA é canalizado aberto; NM/N não modificado/natural.

Desta maneira, estabelece-se a hipótese de que as Ottobacias cujos canais não foram modificados possuem proporções de área impermeabilizada significativamente diferentes de Ottobacias cujos canais foram alterados (canalizados abertos ou subterrâneos). Para avaliar esta hipótese foi aplicado o teste de Kruskal-Wallis.

O Kruskal-Wallis é um teste estatístico não paramétrico utilizado para testar a hipótese nula de que todas as populações possuem funções de distribuição iguais, contra a hipótese alternativa de que, ao menos, duas das populações possuem funções de distribuição diferentes (KRUSKAL; WALLIS, 1952). Este teste avalia 
as diferenças entre três ou mais grupos amostrados independentemente em uma única variável contínua com distribuição não normal. É uma alternativa à análise de variância unidirecional (ANOVA), que é um teste paramétrico adequado para variáveis contínuas com distribuição normal (VARGHA; DELANEY, 1998).

Com relação à avaliação conjunta destas três categorias, a Tabela 3 apresenta um resumo dos resultados do teste não paramétrico de Kruskal-Wallis. Constatou-se que as Ottobacias cujos canais de drenagem estão modificados, subterrâneos ou abertos, não apresentam diferenças significativas entre si. Contudo, no que diz respeito a proporção e área impermeabilizada, diferem significativamente das Ottobacias com canais não modificados.

Neste sentido, tais resultados indicam uma relação direta entre a condição da rede de drenagem em meio urbano com grau de desnaturalização da bacia. Assim, espera-se que, na medida em que aumentem as porções impermeáveis das bacias hidrográficas, tal condição esteja refletida na alteração da rede de drenagem. Ou seja, quanto maior o grau de desnaturalização de uma bacia em ambiente urbano, maior será possibilidade de a rede de drenagem imediata se apresentar modificada.

Tabela 3: Resumo de resultados do teste não paramétrico de Kruskal-Wallis.

Comparações múltiplas para porcentagens da área impermeabilizada

\begin{tabular}{ccccc} 
Categoria 1 & Categoria 2 & $\begin{array}{c}\text { Diferença } \\
\text { Observada }\end{array}$ & Diferença Crítica & $\begin{array}{c}\text { Diferença } \\
\text { Significativa }\end{array}$ \\
\hline Canalizado Subterrâneo & Canalizado Aberto & 4,99 & 15,37 & Não \\
Canalizado Aberto & Não Modificado / Natural & 15,35 & 15,12 & Sim \\
Canalizado Subterrâneo & Não Modificado / Natural & 20,34 & 10,28 & Sim \\
\hline
\end{tabular}

\section{Considerações finais}

O presente estudo teve por objetivo avaliar do ponto de vista teórico e prático a interdependência e sincronicidade dos processos de desnaturalização que ocorrem no rio e na bacia hidrográfica. De maneira complementar, buscou também avaliar como a interdependência destes processos é abordada nos trabalhos de recuperação de rios urbanos.

A revisão da literatura permite as seguintes considerações: 1) diferentes processos de desnaturalização ocorrem simultaneamente e de forma interdependente no rio e na bacia hidrográfica; 2) há uma gama de projetos de recuperação de rios urbanos degradados com diferentes abordagens e propósitos, dentre os quais, destacam-se os conceitos revitalização e renaturalização de rios; 3) tais projetos voltam-se especialmente aos processos que ocorrem estritamente nos rios, desconsiderando os processos desnaturalizantes que se dão na bacia hidrográfica, fato este que conduz ao insucesso de muitos deles; 4) não foram encontrados estudos na literatura que investiguem o quanto os processos de desnaturalização que ocorrem no rio podem estar atrelados aos processos hidrológicos que ocorrem na bacia em ambientes urbanos.

A aplicação prática foi realizada na bacia hidrográfica córrego do Aviário, que possui características comuns a muitas outras áreas urbanas do país, o que torna a bacia representativa no contexto urbano brasileiro. A bacia foi compartimentada em Ottobacias, utilizadas como unidades individualizadas de análise. Foi realizado o mapeamento de áreas impermeáveis, bem como da condição dos canais fluviais. A quantificação e as análises estatísticas foram realizadas para avaliação do grau de relação entre a desnaturalização das Ottobacias e seus respectivos segmentos de rio.

A aplicação prática do método permitiu as seguintes conclusões: 1) as modificações verificadas na rede de drenagem são um reflexo da impermeabilização do solo ou desnaturalização das Ottobacias analisadas; 2) como consequência desta dinâmica já consolidada, é possível afirmar que, de maneira geral, os canais modificados estão associados a Ottobacias predominantemente impermeabilizadas. Do mesmo modo, canais mais próximos de suas condições naturais encontram-se normalmente em áreas menos impermeabilizadas; 3 ) não há associação de canais considerados naturais em áreas com altas proporções de impermeabilização; 4) ademais, infere-se que uma vez modificados, com retificação e canalização aberta, a condição de desnaturalização dos canais de drenagem tende a evoluir para um grau de modificação mais elevado, com canalização subterrânea.

De maneira geral, conclui-se que a metodologia empregada no presente estudo, do ponto de vista teórico e prático, com abordagem voltada a interdependência e sincronicidade que se dão nos processos que ocorrem 
no rio e na bacia hidrográfica bacia, pode ser utilizada como ferramenta para diagnostico no planejamento do espaço urbano e na recuperação de rios degradados.

\section{Referências}

ASSUMPÇÃO, A. P.; MARÇAL, M. S. Retificação dos canais fluviais e mudanças geomorfológicas na planície do rio Macaé (RJ). Revista de Geografia (UFPE), Recife, v. 29, n. 3, p. 19-36, 2012.

AWS - Anacostia Wathershed Society. Anacostia Wathershed Society. Maryland, EUA, 2019. Disponível em: http://www.anacostiaws.org/. Acesso em: abril de 2019.

BARBOSA, D. S.; ESPÍNDOLA, E. L. G; MENDIONDO, E. M. Diretrizes ecológicas em projetos de recuperação de rios urbanos tropicais: estudo de caso no rio Tijuco Preto. $7^{\circ}$ SILUSBA, São Carlos/SP, 2005.

BINDER, W. Rios e Córregos, Preservar, Conservar, Renaturalizar: A Recuperação de Rios, Possibilidades e Limites da Engenharia Ambiental. 3. ed. Rio de Janeiro: SEMADS, 2001.41 p.

BINDER, W. Case Studies: Isar - Germany. In: Expo Zaragoza 2008 (Exposición Internacional Agua y Desarrollo Sostenible), Zaragoza, 2008.

BOTELHO, R. G. M. Bacias Hidrográficas Urbanas. In: GUERRA, A. J. T. (org.). Geomorfologia Urbana. Rio de Janeiro: Bertrand Brasil, 2011. cap. 3, p. 71-115.

BOER, C.; BRESSERS, H. Analyzing the renaturalization of the Dutch Regge river: Complex and Dynamic Implementation Processes. Netherlands: University of Twente, 2011.

CARVALHO, J. W. L. T. Configuração urbana e balanço hídrico com aplicação do modelo Aquacycle na bacia hidrográfica do rio Belém - Curitiba/PR. 2016. 136 p. Dissertação (Mestrado em Geografia) Departamento de Geografia, Universidade Federal do Paraná, Curitiba, 2016.

CUNHA, S. B. Rios desnaturalizados. In: BARBOSA, J. L. (org.). Ordenamento Territorial e Ambiental. 1. ed. Niterói: EDUFF, 2012, cap. 8, p. 171-19.

DINIZ, L. F. M.; GOULART, E. M. A.; LISBOA, A.H. Projeto Manuelzão: a história da mobilização que começou em torno de um rio. Belo Horizonte: Instituto Guaicuy, 2008.

FINDLAY, J. S.; TAYLOR, M. P. Why rehabilitate river systems? Royal Gepgraphical Society. 2006

GORDARD, G. Eventos pluviais extremos e riscos hidrometeorológicos híbridos na bacia do Alto Iguaçu (Paraná). 2019. 234 p. Dissertação (Mestrado em Geografia) - Departamento de Geografia, Universidade Federal do Paraná, Curitiba, 2019.

KATZ, C.; REID, P.; ANDRADE, M. Tres visiones sobre el río Mapocho. ARQ, Santiago, n. 72, p. 56-59, 2009. DOI 10.4067/S0717-69962009000200011

KRUSKAL, W. H.; WALLIS, W. A. Use of ranks in one-criterion variance analysis. Journal of the American Statistical Association. v.47, n. 260, p.583-621, 1952. DOI 10.2307/2280779

LEE, J; PAK, G.; YOO, C.; KIM, S.; YOON, J. Effects of land use change and water reuse options on urban water cycle. Journal of Environmental Sciences, n. 22(6), p. 923-928, 2010. DOI 10.1016/S10010742(09)60199-6

LEKKAS, D. F.; MANOLI, E.; ASSIMACOPOULOS, D. Integrated urban water modelling using the Aquacycle model. Global NEST Journal, v. 10, n. 3, p. 310-319, 2008.

MACHADO, A. T. M. A construção de um programa de revitalização na bacia do Rio São Francisco Estudos Avançados. 22 (63), São Paulo, 2008. 
MARTINS, J. R. C. Uso de técnicas urbanísticas para mitigação da impermeabilização: Parques Lineares. São Paulo: USP, 2015.

MEJÍA, A., DALY, E., ROSSEL, F., JOVANOVIC, T., GIRONAS, J. A stochastic model of streamflow for urbanized basins. Water Resources Research, v. 50, n. 3, p. 1984-2001, $2014 . \quad$ DOI 10.1002/2013WR014834

MINEROPAR. Atlas Geomorfológico do Estado do Paraná - Escala base 1:250.000, modelos reduzidos 1: 500.000 / Minerais do Paraná; Universidade Federal do Paraná. Curitiba, 2006.

MITCHELL, G.; MEIN, R.; MCMAHON, T. A. Modelling the urban water cycle. Journal of Environmental Modelling and Software. v. 16, n. 7, p. 615-629, 2001. DOI 10.1016/S13648152(01)00029-9

PALMER, A. M.; MENNINGER, H.; BERNHARDT, E. River restoration, habitat heterogeneity and biodiversity: a failure of theory or practice? Freshwater Biology. v. 55, p. 205-222, 2010. DOI 10.1111/j.1365-2427.2009.02372.x

PALMER, A. M.; RUHI, A. Linkages between flow regime, biota, and ecosystem processes: Implications for river restoration. Science, Nova York, v. 365, n. 6459, p. eaaw2087, 2019. DOI 10.1126/science.aaw2087

PFAFSTETTER, O. Classificação de bacias hidrográficas. Rio de Jeneiro: Departamento Nacional de Obras de Saneamento, 1989.

RUTHERFURD, I. D. JERIE, K.; MARSH, N. A Rehabilitation Manual for Australian Streams. Melbourn: Land and Water Resources Research and Development Corporation and Cooperative Research Centre for Catchment Hydrology. v. 2, 2000.

RUTHERFURD, I. D.; JERIE, K.; MARSH, N. A Rehabilitation Manual for Australian Streams. Melbourn: Land and Water Resources Research and Development Corporation and Cooperative Research Centre for Catchment Hydrology. v.2, 2000.

SARTÓRIO, M. V. O. Desnaturalização dos sistemas fluviais urbanos: o caso do canal da costa e do canal Bigossi, Vila Velha (ES). 2018. 167 p. Dissertação (Mestrado em Geografia) - Universidade Federal do Espírito Santo, Vitória, 2018.

STEVAuX, J. C.; LATRUBESSE, E. M. Geomorfologia Fluvial. MENDONÇA, F. A. (org.) Coleção Geografia, v. 3. São Paulo: Oficina de Textos, 2017.

TUCCI, C. E. M. Gerenciamento da drenagem urbana. Revista Brasileira de Recursos Hídricos. v. 7, n. 1, p. 5-27, jan-mar, 2002.

TUCCI, C. E. M. Águas Urbanas. Estudos Avançados. v. 22, n. 63, p. 97-112, 2008.

VARGHA, A.; DELANEY, H. D. The Kruskal-Wallis Test and Stochastic Homogeneity. Journal of Educational and Behavioral Statistics. v. 23, n. 2, p. 170-192, 1998. DOI 10.3102/10769986023002170

WWC - World Water Council. Start With Water: Putting water on local action agendas to support global change. Marseille: 2018

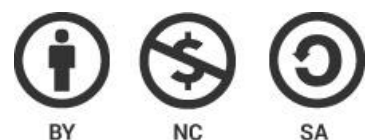

Este artigo é distribuído nos termos e condições do Creative Commons Attributions/AtribuiçãoNãoComercial-CompartilhaIgual (CC BY-NC-SA). 